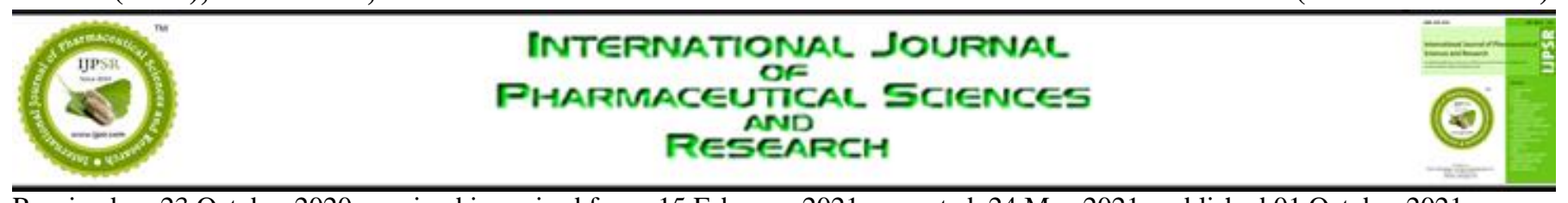

Received on 23 October 2020; received in revised form, 15 February 2021; accepted, 24 May 2021; published 01 October 2021

\title{
FORMULATION AND EVALUATION OF METOPROLOL LOADED SOLID LIPID NANOPARTICLES
}

\section{G. Bhanusri * and P. Tripura Sundari}

R. B. V. R. R Women's College of Pharmacy, Barkatpura, Hyderabad - 500027, Telangana, India.

Keywords:

Metoprolol, Solid lipid nanoparticles, Compritol, and Hot homogenization

Correspondence to Author:

G. Bhanusri

M. Pharmacy,

R. B. V. R. R Women's College of

Pharmacy, Barkatpura, Hyderabad -

500027, Telangana, India.

E-mail: g.bhanusri52@gmail.com
ABSTRACT: The main aim of the present study is to formulate and evaluate solid lipid nanoparticles of Metoprolol. Metoprolol is an anti-hypertension drug used in the treatment of hypertension, angina pectoris, and heart failure. Metoprolol belongs to BCS class-I, which has high solubility and high permeability. The drug needs to be administered frequently (2-3 times a day), and it has side effects and poor bioavailability of $40-50 \%$ drug through oral administration. In order to avoid the side effects and to improve its bioavailability and sustained release of the drug, there is a need to develop Metoprolol-loaded solid lipid nanoparticles. In the present study, solid lipid nanoparticles of Metoprolol were prepared by the Hot Homogenization technique. In this solid lipid nanoparticles of Metoprolol, employing Compritol as the carriers and Tween 80, PEG-400 and soya lecithin as surfactant systems and were evaluated for various parameters like entrapment efficiency, drug content and in-vitro drug release, particle size and zeta potential. The C8(1:3) formulation showed better results entrapment efficiency of $98.20 \%$, drug content of $82.10 \%$ and $48.16 \%$ of drug release for a period of $6 \mathrm{~h}$, particles of the size of 286.7-386.9 $\mathrm{nm}$ and zeta potential value of $-29.4 \mathrm{mV}$. The present study demonstrated that Metoprolol can be successfully formulated into solid lipid nanoparticles to improve its bioavailability and sustained release of the drug.
INTRODUCTION: The oral route of drug administration is one of the best convenient and commonly used routes for the delivery of the drugs because it's therapeutic advantages such as convenience to administration, patient compliance, cost-effectiveness and flexibility in formulation. However, this route has several physiological problems, such as aqueous solubility, first-pass metabolism, drug permeability, pre systemic metabolism, frequent administration and which normally means $2-3 \mathrm{~h}$ through the major absorption zone.

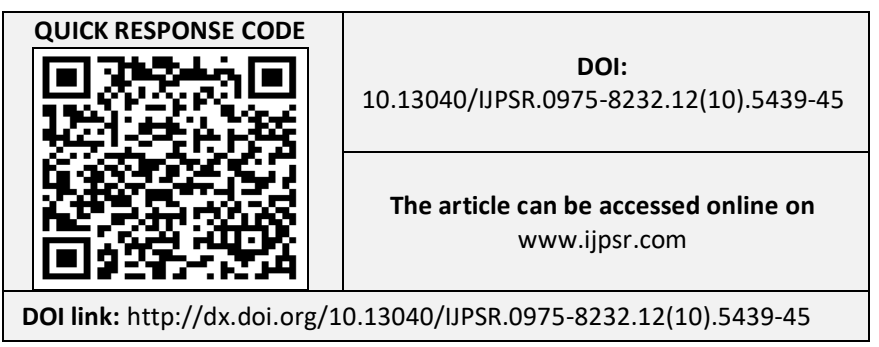

Overcome these problems can be solved by converting them into nano-carrier systems. Novel drug delivery systems are mostly used to develop a sustained and controlled drug delivery system, which can provide therapeutically effective plasma drug concentration for a longer period, thereby reducing the dosing frequency and minimizing fluctuations in plasma drug concentration and reduces side effects and also improve the bioavailability.

Various novel techniques used to enhance solubility and bioavailability are solid lipid nanoparticles, polymeric nanoparticles, Self emulsifying drug delivery systems, solid dispersions, etc. Based upon the problem associated with the drug, the technique that is to be employed must be chosen. Here we chose solid lipid nanoparticles for the study of this drug Metoprolol. Metoprolol Succinate is a beta1-selective 
adrenergic receptor blocking agent (antihypertensive). Which has wide therapeutic activities and practically highly soluble in water and has poor bioavailability, it is BCS class-I drug. This drug need to be administered frequently (usually 2-3 times a day) leads to cause adverse effects. It is available commercially in $25-100 \mathrm{mg}$ and $100 \mathrm{mg}$ strength as immediate release tablets with bioavailability of $40-50 \%$ following oral administration. This class of drugs shows frequent administration and less bioavailability leads to fluctuations in plasma concentration, suboptimum therapeutic level, less effective management of the disease and less patient compliance. To overcome these drawbacks, increasing the bioavailability, reduce the drug dose, side effects and sustained drug release of Metoprolol is an important goal. Possible various techniques to avoid first pass metabolism include transdermal, buccal, rectal and parenteral route of administration. But conventional preparations like solution, suspension or emulsion for drug delivery purpose has various boundaries like high dose and low availability, faster reach effect and which do not provide sustained release of drug as well as reaching of drug to target site without any alteration in its physical and chemical properties.

Therefore, some novel carriers which could improve the above problems by reaching to its target site in the body without making any adverse effects to body and can carry the drug easily and safely to its target place. Nanoparticles (NP) are a type of colloidal drug delivery system such solid lipid nanoparticles with a size range from 50-1000 $\mathrm{nm}$. The major advantages of these nanoparticles are improved bioavailability, therapeutic therapy, aqueous solubility and increasing resistance time in the body. Solid lipid nanoparticles are the method of hot homogenization used as control and target drug release and increased drug stability. So the solid lipid nanoparticles are used to help improving the above mention conventional drug delivery disadvantages.

\section{MATERIALS AND METHODS:}

Materials: Metoprolol was purchased from Ravoos Laboratories Limited; Compritol by Sun Pharmaceutical Industries Ltd, Soya lecithin (HiMedia laboratories), Tween 80 (S.D. fine chemicals) and dialysis membrane (HiMedia, Mumbai). All other reagents used were of analytical grade.

Drug Profile: Metoprolol Succinate is antihypertensive drug. It is used in the treatment of hypertension, angina pectoris and heart failure. Metoprolol molecular Formula is $\left(\mathrm{C}_{15} \mathrm{H}_{25} \mathrm{NO}_{3}\right) 2$ • $\mathrm{C}_{4} \mathrm{H}_{6} \mathrm{O}_{4}$. It is BCS class I and it is freely soluble in water; soluble in methanol; sparingly soluble in ethanol; slightly soluble in dichloromethane and 2propanol; practically insoluble in ethyl acetate, acetone, diethyl ether and heptane. The bioavailability of Metoprolol is $40-50 \%$.

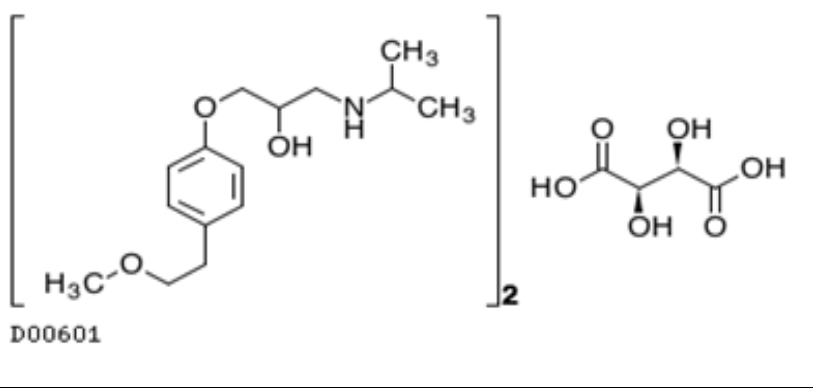

STRUCTURE OF METOPROLOL

Mechanism of Action: Relatively cardio selective beta1-adrenoreceptor blocking drug without intrinsic sympathomimetic activity. Reducing blood pressure and myocardial oxygen demand.

Preparation of Metoprolol Loaded Solid Lipid Nanoparticles: Metoprolol loaded Solid lipid nanoparticles were prepared by hot homogenization followed by the sonication method.

TABLE 1: FORMULATION OF METOPROLOL SOLID LIPID NANOPARTICLES BY HOT HOMOGENIZATION METHOD

\begin{tabular}{ccccccccc}
\hline Ingredients & C1 & C2 & C3 & C4 & C5 & C6 & C7 & C8 \\
\hline Metoprolol & $10 \mathrm{mg}$ & $10 \mathrm{mg}$ & $10 \mathrm{mg}$ & $10 \mathrm{mg}$ & $10 \mathrm{mg}$ & $10 \mathrm{mg}$ & $10 \mathrm{mg}$ & $10 \mathrm{mg}$ \\
Compritol & $1 \mathrm{gm}$ & $1 \mathrm{gm}$ & $1 \mathrm{gm}$ & $1 \mathrm{gm}$ & $1 \mathrm{gm}$ & $1 \mathrm{gm}$ & $1 \mathrm{gm}$ & $1 \mathrm{gm}$ \\
Soya lecithin & $100 \mathrm{mg}$ & $100 \mathrm{mg}$ & $100 \mathrm{mg}$ & $100 \mathrm{mg}$ & $100 \mathrm{mg}$ & $100 \mathrm{mg}$ & $100 \mathrm{mg}$ & $100 \mathrm{mg}$ \\
Tween-80 & $50 \mathrm{mg}$ & $100 \mathrm{mg}$ & $200 \mathrm{mg}$ & $300 \mathrm{mg}$ & & & & \\
PEG-400 & & & & & $50 \mathrm{mg}$ & $100 \mathrm{mg}$ & $200 \mathrm{mg}$ & $300 \mathrm{mg}$ \\
Distilled water & $20 \mathrm{ml}$ & $20 \mathrm{ml}$ & $20 \mathrm{ml}$ & $20 \mathrm{ml}$ & $20 \mathrm{ml}$ & $20 \mathrm{ml}$ & $20 \mathrm{ml}$ & $20 \mathrm{ml}$ \\
\hline
\end{tabular}




\section{Hot Homogenization Method:}

Procedure: In the hot homogenization technique, the drug was dispersed in the lipid (Compritol) and Soya lecithin (hydrophobic surfactant) by melting them above $70{ }^{\circ} \mathrm{C}$ of their melting point. This is considered as the lipid phase. The aqueous phase was prepared by adding hydrophilic surfactant (Tween 80 and PEG-400) in the distilled water and heated $\left(70-80{ }^{\circ} \mathrm{C}\right)$ to the temperature of the lipid phase. The lipid phase was added to the aqueous phase slowly, drop by drop under continuous stirring at $2700 \mathrm{rpm}$ for about $3 \mathrm{~h}$. The formulation was further sonicated for half an hour and cooled to room temperature. At room temperature the lipid was recrystallized to the formation of Solid Lipid Nanoparticles.

\section{Characterization of Metoprolol Loaded Solid Lipid Nanoparticles:}

Drug Content: $1 \mathrm{ml}$ of prepared Solid lipid nanoparticles suspension was dissolved in the 10 $\mathrm{ml}$ of $\mathrm{pH} 6.8$ phosphate buffer solution. The amount of Metoprolol was determined by using UV spectrophotometer at $222 \mathrm{~nm}$.

Entrapment Efficiency: Entrapment efficiency indicates the amount of drug entrapped in the prepared formulation. $1 \mathrm{ml}$ of prepared SLNs suspension was taken and dissolved in $10 \mathrm{ml}$ of 6.8 PH buffer, kept for ultracentrifuge with $15000 \mathrm{rpm}$ speed for $30 \mathrm{~min}$ at $0{ }^{\circ} \mathrm{C}$. The supernatant drug content was calculated by using the formula,

$\mathrm{EE}=\{$ total drug content-free drug content/ total drug content $\} \times 100$

From the supernatant portion. The absorbance was measured at $222 \mathrm{~nm}$ in UV spectrophotometer to calculate the entrapment efficiency.

Percentage entrapment efficiency was calculated from the following equation:

E.E $=$ Amount of total drug - Amount of drug in aqueous phase / Amount of total drug $\times 100$

In-vitro Dissolution Study: An accurate $1 \mathrm{ml}$ of Metoprolol SLNs was taken into the dialysis membrane bag and sealed. This sealed dialysis bag was then suspended into the dissolution basket containing $900 \mathrm{ml}$ of phosphate buffer saline solution of $\mathrm{pH} 6.8$ at the temperature of $37 \pm 2{ }^{\circ} \mathrm{C}$, and stirred at a constant speed of $100 \mathrm{rpm}$.
Aliquots were collected at the time intervals like 1, $2,3,4,5,6$, up to $12 \mathrm{~h}$ and the same was replaced with the fresh buffer.

The drug content was determined spectrophotometry by measuring the absorbance at $222 \mathrm{~nm}$ using the same buffer solution as the blank to calculate the amount of drug released from the nanoparticles.

Particle Size Distribution, Particle Size, and Zeta Potential: The particle size and particle size distribution of the formulation were determined by using the photo correlation spectroscopy with a zeta master (Malvern Instruments, UK) equipped with the Malvern PCS software. Every sample was prepared by using diluted with double distilled water.

The Zeta potential was determined by measuring the electrophoretic mobility of the nanoparticles using a Malvern zeta sizer (Malvern Instruments, UK). Samples were prepared by using diluted with double distilled water.

\section{RESULTS AND DISCUSSION:}

Construction of Standard Plot for Metoprolol in pH 6.8 Phosphate Buffer: The UV-Visible Spectrophotometric calibration curve for analysis in pH 6.8 phosphate buffer was developed. The plot was drawn between concentrations versus absorbance as represented in the above figure.

The linear relationship between the concentrations of Metoprolol on the corresponding absorbance values has confirmed that they obey Beers Law in the concentration range of $2-10 \mu \mathrm{g} / \mathrm{ml}$.

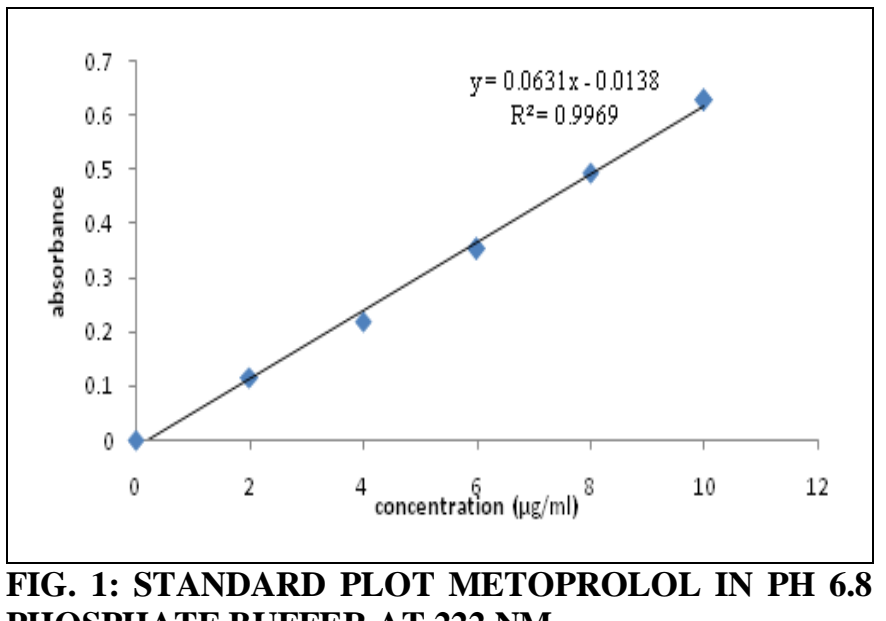


A positive correlation between the concentration of Metoprolol and the corresponding absorbance values was observed. (Correlation coefficient, $\mathrm{R}^{2}=$ $0.9969)$ in buffer.
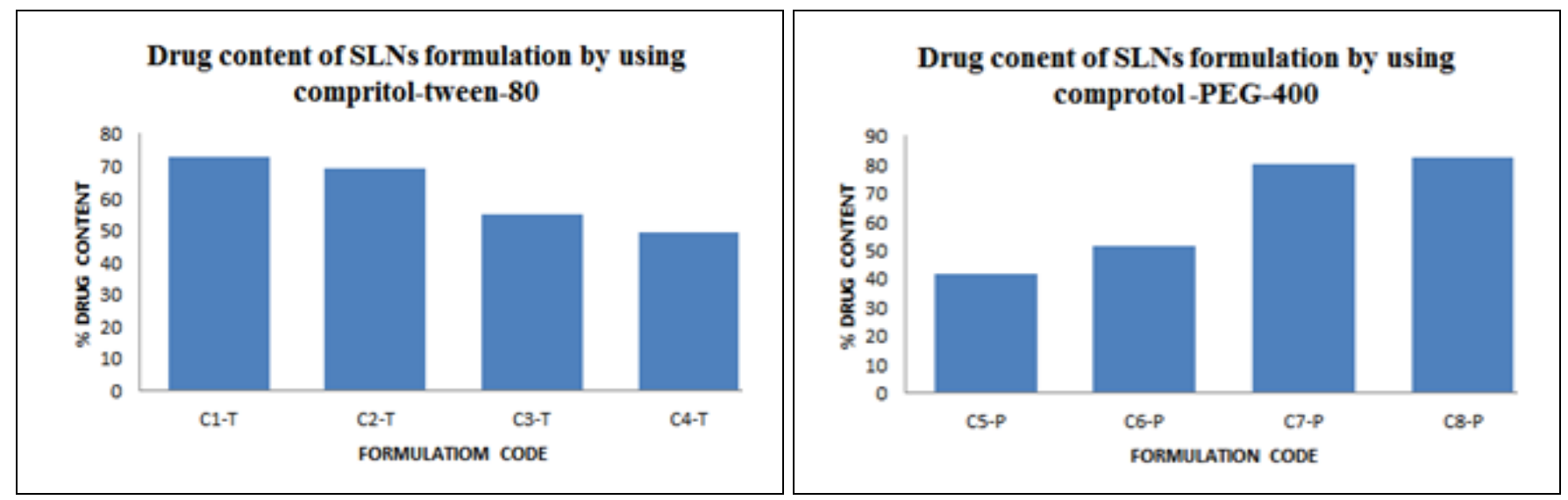

FIG. 2: DRUG CONTENT OF METOPROLOL SOLID LIPID NANOPARTICLES USING COMPRITOL- TWEEN80 \& PEG-400 BY HOT HOMOGENIZATION METHOD Among all the formulation, C8 formulation showed best drug content of $82.10 \%$.

TABLE 2: DRUG CONTENT OF METOPROLOL SOLID LIPID NANOPARTICLES BY HOT HOMOGENIZATION METHOD EMPLOYING COMPRITOL-TWEEN-80 \& PEG-400

\begin{tabular}{cc}
\hline Formulation code & Drug content $(\%)$ \\
\hline C1-T & $72.75 \pm 0.3$ \\
C2-T & $69.28 \pm 0.4$ \\
C3-T & $54.80 \pm 0.1$ \\
C4-T & $49.03 \pm 0.4$ \\
C5-P & $41.44 \pm 0.3$ \\
C6-P & $51.12 \pm 0.6$ \\
C7-P & $79.97 \pm 0.1$ \\
C8-P & $82.10 \pm 0.4$ \\
\hline
\end{tabular}

Entrapment efficiency of SLNs formulation by using compritol-Tween-80

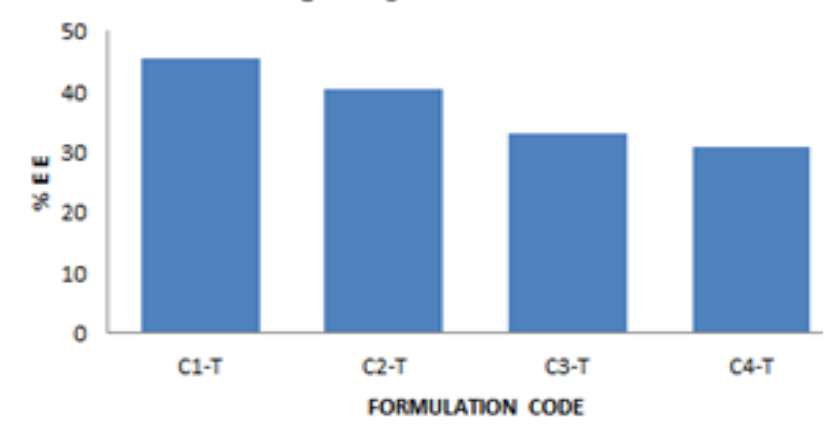

TABLE 3: ENTRAPMENT EFFICIENCIES OF METOPROLOL SOLID LIPID NANOPARTICLES BY HOT HOMOGENIZATION METHOD BY EMPLOYING COMPRITOL- TWEEN-80 \& PEG-400

\begin{tabular}{cc}
\hline Formulation code & Entrapment efficiency $(\%)$ \\
\hline C1-T & $45.48 \pm 0.3$ \\
C2-T & $40.27 \pm 0.1$ \\
C3-T & $33.04 \pm 0.5$ \\
C4-T & $30.89 \pm 0.2$ \\
C5-P & $23.36 \pm 0.4$ \\
C6-P & $33.10 \pm 0.3$ \\
C7-P & $97.70 \pm 0.4$ \\
C8-P & $98.20 \pm 0.2$ \\
\hline
\end{tabular}

Entrapment efficiency of SLNs formulation by using compritol-PEG-400

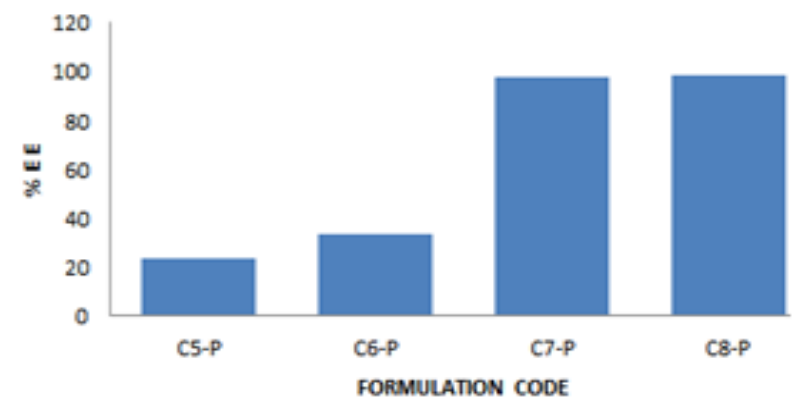

FIG. 3: ENTRAPMENT EFFICIENCIES OF FORMULATIONS OF METOPROLOL SOLID LIPID NANOPARTICLES COMPRITOL- TWEEN-80 \& PEG-400 Among all the formulations, C8 formulation showed maximum drug entrapment efficiency of $98.20 \%$.

TABLE 4: IN-VITRO DRUG RELEASES OF FORMULATIONS OF NANOPARTICLES BY HOT HOMOGENIZATION METHOD BY EMPLOYING COMPRITOL- TWEEN-80 \& PEG-400

\begin{tabular}{ccccccccc}
\hline Time & C1-T & C2-T & C3-T & C4-T & C5-P & C6-P & C7-P & C8-P \\
\hline $1 \mathrm{~h}$ & $16.65 \pm 0.5$ & $14.65 \pm 0.4$ & $13.87 \pm 0.1$ & $9.12 \pm 0.3$ & $23.55 \pm 0.03$ & $19.95 \pm 0.33$ & $16.64 \pm 0.02$ & $10.65 \pm 0.3$ \\
$2 \mathrm{~h}$ & $27.23 \pm 0.4$ & $24.60 \pm 0.3$ & $23.55 \pm 0.1$ & $19.36 \pm 0.2$ & $30.23 \pm 0.15$ & $32 \pm 0.06$ & $20.41 \pm 0.33$ & $20.33 \pm 0.02$ \\
$3 \mathrm{~h}$ & $30.43 \pm 0.1$ & $37.43 \pm 0.2$ & $34.20 \pm 0.5$ & $28.56 \pm 0.1$ & $39.60 \pm 0.63$ & $37.95 \pm 0.19$ & $25.94 \pm 0.1$ & $21.38 \pm 0.61$ \\
$4 \mathrm{~h}$ & $44.23 \pm 0.5$ & $42.76 \pm 0.1$ & $45.98 \pm 0.2$ & $42.24 \pm 0.3$ & $52.51 \pm 0.14$ & $44.95 \pm 0.3$ & $36.21 \pm 0.06$ & $30 \pm 0.03$ \\
$5 \mathrm{~h}$ & $48.12 \pm 0.1$ & $49.28 \pm 0.1$ & $53.56 \pm 0.4$ & $51.36 \pm 0.1$ & $67.51 \pm 0.31$ & $57.98 \pm 0.02$ & $41.74 \pm 0.19$ & $40.66 \pm 0.14$ \\
$6 \mathrm{~h}$ & $70.45 \pm 0.3$ & $66.66 \pm 0.3$ & $64.51 \pm 0.1$ & $62.8 \pm 0.2$ & $76.55 \pm 0.01$ & $67.99 \pm 0.1$ & $55.72 \pm 0.05$ & $48.16 \pm 0.31$ \\
\hline
\end{tabular}



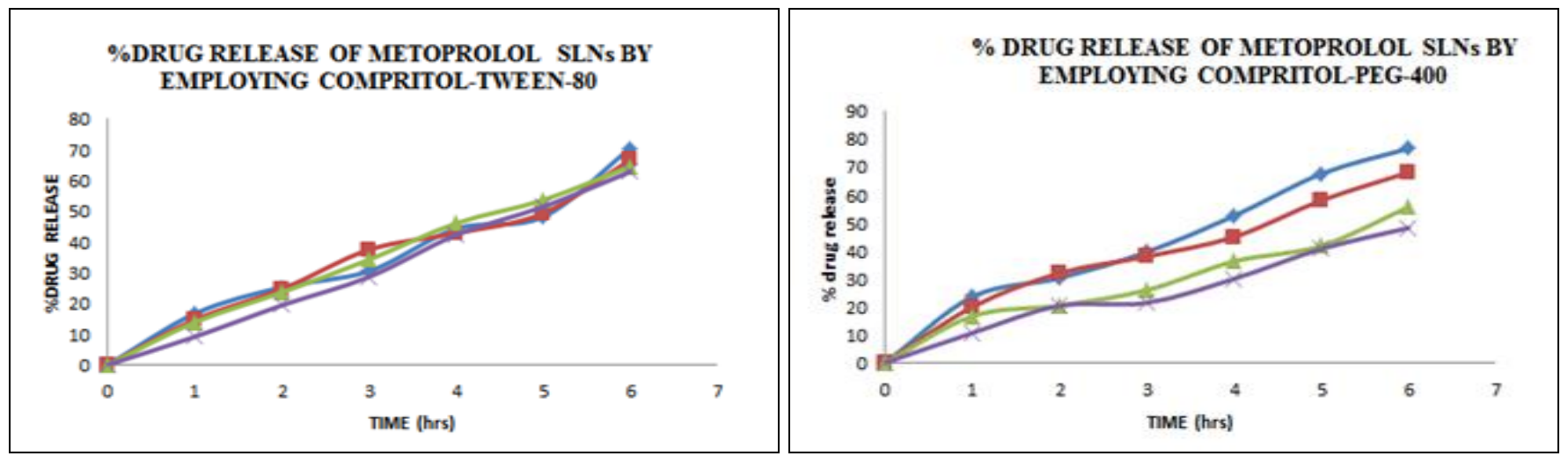

FIG. 4: IN-VITRO KINETIC PLOTS OF METOPROLOL SOLID LIPID NANOPARTICLES USING COMPRITOL TWEEN-80 \& PEG-400 BY HOT HOMOGENIZATION METHOD

In-vitro drug release studies were performed for a period of $6 \mathrm{~h}$. The percent drug release for the prepared formulations was calculated. The drug release of prepared formulation were found to be
$70.45 \%, 66.66 \%, 64.51 \%, 62.8 \%, 76.55 \%, 67.99 \%$, $55.72 \%$ and $48.16 \%$. Among all the formulations C8 was found to be the best formulation as it showing drug release $48.16 \%$.

\section{TABLE 5: FITTING OF DATA INTO KINETIC PLOTS OF METOPROLOL SOLID LIPID NANOPARTICLES}

\begin{tabular}{ccccc}
\hline Formulation & Zero order $\operatorname{plot}\left(\mathbf{R}^{\mathbf{2}}\right)$ & First $\operatorname{order} \operatorname{plot}\left(\mathbf{R}^{\mathbf{2}}\right)$ & Higuchi $\operatorname{plot}\left(\mathbf{R}^{\mathbf{2}}\right)$ & Peppas plot(n) \\
\hline C 8 & 0.9807 & 0.9353 & 0.9123 & 0.9669 \\
\hline
\end{tabular}

The drug release data was fitted in various kinetic plots (zero order, first order, higuchi and peppas) in order to determine the order and mode of drug release. According to the kinetic plots, the optimized formulation $\mathrm{C} 8$ was following the Higuchi plot, peppas plot release with mechanism of matrix diffusion (by Higuchi plot) and fickian diffusion (by $n$ value in peppas).
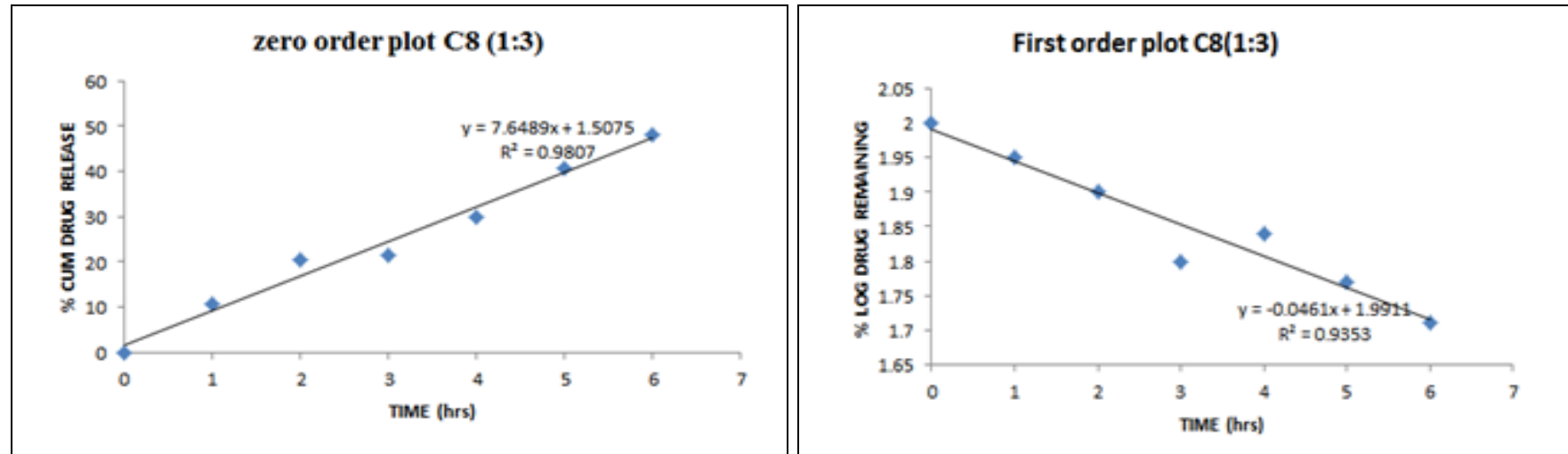

FIG. 5: IN-VITRO KINETIC PLOTS OF METOPROLOL SOLID LIPID NANOPARTICLES USING COMPRITOL - PEG400 BY HOT HOMOGENIZATION METHOD
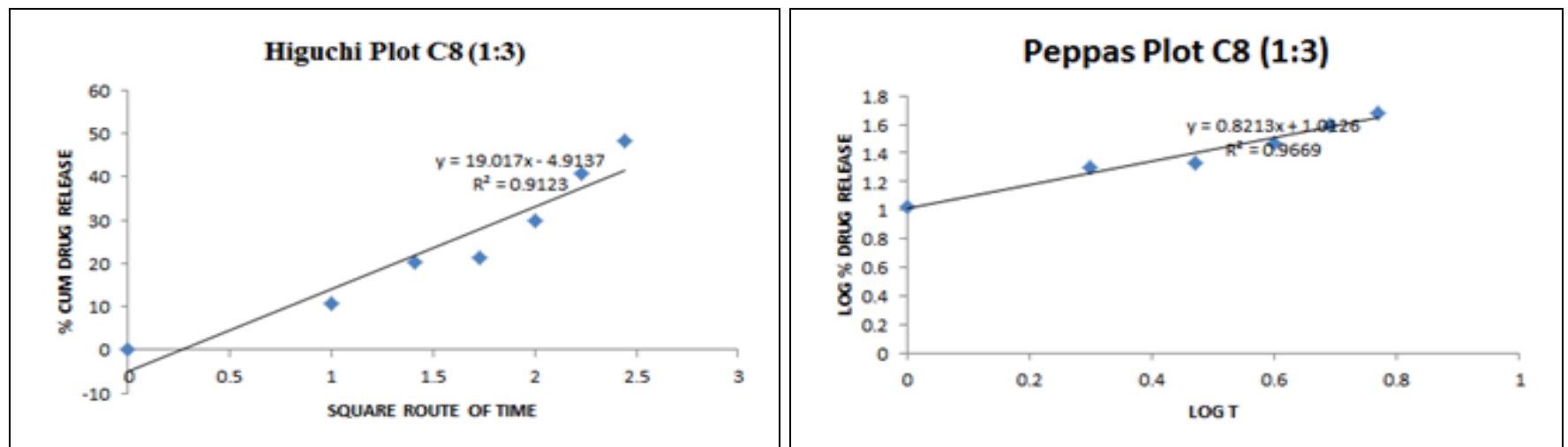

FIG. 6: PARTICLE SIZE REPORT OF C8 FORMULATION OF METOPROLOL SOLID NANOPARTICLES BY HOT HOMOGENIZATION METHOD 


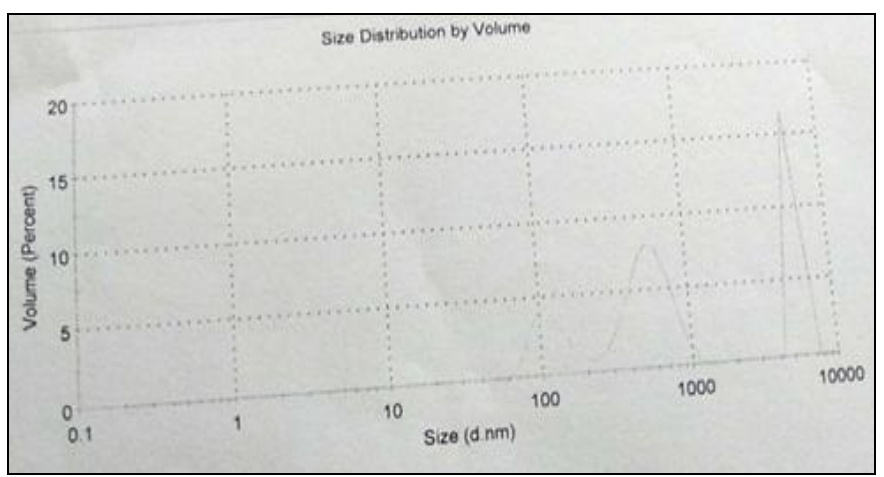

THE C8 FORMULATION CONTAINED PARTICLES OF SIZE OF 286.7- 386.9 NM

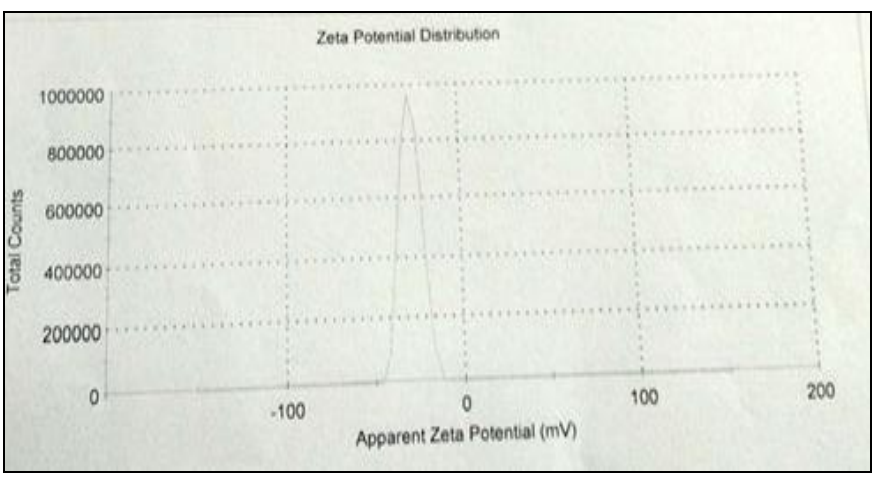

FIG. 7: ZETA POTENTIAL REPORT OF $\quad$ C8 FORMULATION OF METOPROLOL SOLID LIPID NANOPARTICLE The best formulation of C8 showed the zeta potential value of $-29.4 \mathrm{mV}$

DISCUSSION: Metoprolol succinate is a cardio selective $\beta$-blocker used in the treatment of hypertension, heart failure and angina pectoris. This drug need to be administered frequently (usually 2-3 times a day) has adverse effects and low bioavailability of $40-50 \%$ through oral administration. In order to avoid the side effects and improve the bioavailability of Metoprolol there is a need to develop novel drug delivery system. Like to develop Metoprolol loaded solid lipid nanoparticles. This will maintain the concentration of drug in blood for longer time with controlled and sustained release of drug from it. And also improve the bioavailability of Metoprolol drugs.

Metoprolol-loaded solid lipid nanoparticles were prepared by hot homogenization technique. The total 8formulations (C1-C8) were prepared by varying lipid: surfactant ratio $(1: 0.5,1: 1,1: 2,1: 3)$ i.e. by increasing surfactant concentration $(50 \mathrm{mg}$, $100 \mathrm{mg}, 200 \mathrm{mg}, 300 \mathrm{mg}$ ) and by using Tween-80 and PEG-400 as surfactant and the lipid (Compritol) was $1 \mathrm{~g}$ in all the 8 formulations. On comparison of all the prepared Metoprolol solid lipid nanoparticles formulations (C1-C8), the $\mathrm{C} 8$
(1:3) formulation is showing better results having drug content of $82.10 \%$, entrapment efficiency of $98.20 \%$ and $\%$ drug release of $48.16 \%$ within $6 \mathrm{~h}$, particles size 286.7-386.9 $\mathrm{nm}$ and zeta potential $29.4 \mathrm{mv}$. The C8 formulation drug release mechanism is followed by matrix diffusion (by Higuchi plot), fickian diffusion (by $\mathrm{n}$ value in peppas).

CONCLUSION: In the present study Metoprolol loaded solid lipid nanoparticles were prepared. Metoprolol-loaded Solid lipid nanoparticles were prepared by using compritol, by employing a hot homogenization method. All the formulations were evaluated for drug content, entrapment efficiency and drug release studies, particle size and zeta potential. Out of all formulations, the best formulations were found to be $\mathrm{C} 8$ with drug content was found to be $82.10 \pm 0.4 \%$, entrapment efficiency was $98.20 \pm 0.2 \%$ and drug release was $48.16 \%$ within $6 \mathrm{~h}$, particles size 286.7-386.9 nm and zeta potential $-29.4 \mathrm{mv}$. Solid lipid nanoparticles are the best suitable formulations for sustained release. The drug release mechanism is followed bymatrix diffusion (by Higuchi plot), fickian diffusion. (by $\mathrm{n}$ value in peppas).

ACKNOWLEDGEMENT: The authors are highly thankful to the department of pharmaceutics, RBVRR women's college of pharmacy, Osmania University for their kind support.

CONFLICTS OF INTEREST: The authors confirm that this research article content has no conflict of interest.

\section{REFERENCES:}

1. Remya PN and Damodharan N: formulation, development and characterization of nimodipine loaded solid lipid nanoparticles. International Journal of Applied Pharmaceutics 2020; 12: (5).

2. Sundari PT and Anushree H: Formulation and evaluation of solid lipid nanoparticles of Quetiapine fumarate, European Journal of Biomedical and Pharmaceutical Sciences 2018; 5(4): 972-9775.

3. Madderla S: Dr. P. Tripura sundari has prepared formulation and evaluation of curcumin loaded solid lipid nanoparticles by hot homogenization method by employing glyceryl monostearate by hot homogenization method.International Journal for Research Trends and Innovation 2018; 3(12).

4. Remya PN: Damodharan $\mathrm{N}$ has prepared formulation, development, and characterization of cilnidipine loaded solid lipid nanoparticles, Asian Journal of Pharmaceutical and Clinical Research 2018; 11(9). 
5. Madderla S: Dr. P. Tripura Sundari has prepared formulation and evaluation of curcumin loaded solid lipid nanoparticles by employing cutina ${ }^{\circledR}$ HR, International Journal of Research and Analytical Reviews 2018; 5(4).

6. Gazi AS: Abbaraju Krishnasailaja has worked Preparation \& evaluation of paracetamol solid lipid nanoparticles by hot homogenization method. Journal of Nanomedicine Research 2018; 7(2).

7. Kipriye $\mathrm{Z}$ and Şenel B: Evrim Yenilmez has worked on Preparation and evaluation of carvedilol-loaded solid lipid nanoparticles for targeted drug delivery by hot homogenization and ultra-sonication methods. Tropical Journal of Pharmaceutical Research 2017; 16(9).

8. P Senthil Kumar and N Punniamurthy: Formulation development and characterization of curcumin loaded solid lipid nanoparticles for improved aqueous solubility and bioavailability; The Pharma Innovation Journal 2017; 6(4): 07-11.

9. Shelata P, Mandowaraa VK, Guptaa DG, Patela S; Formulation of curcuminoid loaded solid lipid nanoparticles in order to improve oral bioavailability; International Journal of Pharmacy and Pharmaceutical Sciences 2015; 7(613).

10. Havanoor SM, Manjunath K and Bhagawati ST: has prepared isradipine loaded solid lipid nanoparticles for better treatment of hypertension - preparation, characterization and in-vivo evaluation by hot homogenization. International Journal of Biopharmaceutics 2014; 5(3): 218-224.

11. Ekambaram P and Sathali AHA: has prepared Formulation and evaluation of solid lipid nanoparticles of ramipril by hot homogenization followed by the ultra-sonication method. Journal of Young Pharmacists 2011; 3(3).

12. Chirio D, Gallarate M, Peira E, Battaglia L, Serpe L and Trotta M; Formulation of curcumin-loaded solid lipid nanoparticles produced by fatty acids coacervation technique; Journal of Microencapsulation 2011; 28(6): 537-48.

13. Joshi V, Ahmed GA, Suresh S and Kowti R: A comparative study: solution stability and dissolution behavior of solid dispersion curcumin, Indian J Nov Drug Deliver 2010; 2(3): 88-95.

14. Mukherjee S, Ray S and Thakur RS: "Solid lipid nanoparticles: A Modern Formulation Approach in Drug Delivery System" Indian journal of Pharm Sci 2009; 71(4): 349-58.

15. Suresh G, Manjunath K, Venkateswarlu V and Satyanarayana V: Preparation, characterization, in-vitro and in-vivo evaluation of lovastatin solid lipid nanoparticles. AAPS Pharm Sci Tech Mar 2007; 23(8): 24.

\section{How to cite this article:}

Bhanusri G and Sundari PT: Formulation and evaluation of metoprolol loaded solid lipid nanoparticles. Int J Pharm Sci \& Res 2021; 12(10): 5439-45. doi: 10.13040/IJPSR.0975-8232.12(10).5439-45.

All @ 2021 are reserved by International Journal of Pharmaceutical Sciences and Research. This Journal licensed under a Creative Commons Attribution-NonCommercial-ShareAlike 3.0 Unported License.

This article can be downloaded to Android OS based mobile. Scan QR Code using Code/Bar Scanner from your mobile. (Scanners are available on Google Playstore) 